\title{
Capillary Supply and Fiber Morphometry in Rat Myocardium after Intermittent Exposure to Hypobaric Hypoxia
}

\author{
PERE PANISELLO, JOAN RAMON TORRELLA, TERESA PAGÉS, and GINÉS VISCOR
}

\begin{abstract}
Panisello, Pere, Joan Ramon Torrella, Teresa Pagés, and Ginés Viscor. Capillary supply and fiber morphometry in rat myocardium after intermittent exposure to hypobaric hypoxia. High Alt. Med. Biol. 8:322-330, 2007.-Three groups of male rats were submitted to an intermittent hypobaric hypoxia ( $\mathrm{IHH})$ program for 22 days ( $4 \mathrm{~h} /$ day, 5 days/week) in a hypobaric chamber at a simulated altitude of $5000 \mathrm{~m}$. Hearts were removed at the end of the program (H group) and 20 and 40 days later (P20 and P40 groups). A control group (C) was maintained at sea-level pressure. Transverse sections from myocardium were cut and histochemically stained in order to measure fiber morphometry and capillaries. We observed a progressive increase from $\mathrm{C}$ to $\mathrm{H}$ to P20 animals in capillary (4124 to 4733 to 4816 capillaries $/ \mathrm{mm}^{2}$ ) and fiber densities (2844 to 3125 to 3284 fibers $\left./ \mathrm{mm}^{2}\right)$ associated with significant reductions in fiber area $\left(273,235\right.$, and $\left.227 \mu \mathrm{m}^{2}\right)$, perimeter $(69,64$, and $62 \mu \mathrm{m})$, and diffusion distances $(18.2,16.9$, and $16.6 \mu \mathrm{m})$. The most significant differences between $C$ and hypoxic groups were found when morphometrical and vascular fiber parameters were combined. The myocardium of the latter had more capillaries per fiber area and per fiber perimeter. These findings indicate that the IHH program elicits an adaptive response of rat myocardium to a more efficient $\mathrm{O} 2$ delivery to mitochondria of cardiac muscle cells. Capillarization and fiber morphometric changes showed marked differences over time. In all cases, P20 had higher capillarization parameters and fiber morphometry reductions than $\mathrm{H}$, thus indicating that a delay of about 20 days exists after the hypoxic stimulus ceases to reach complete angiogenesis and fiber morphometry changes. However, P40 animals showed a recovery to basal values of the parameters related to fiber morphometry (area, perimeter, and diffusion distances), but maintained high capillarity values (capillary density, NCF, CCA, CCP).
\end{abstract}

Key Words: intermittent hypoxia; simulated altitude; capillary density; heart; myocardial capillarization; hypobaric chamber

\section{INTRODUCTION}

A FTER THE PIONEERING BOOK La pression barométrique by Paul Bert (1878) on the physiological effects of altering barometric pressure, many studies have emphasized the importance of research into high altitude physiology and acclimatization (see Kellogg, 1978,

Departament de Fisiologia, Facultat de Biologia, Universitat de Barcelona, Barcelona, Spain.

This paper is dedicated to the memory of Dr. Emilio Aquiles Marticorena Pimentel, who was a pioneer in the application of intermittent hypoxia exposure to cardiac rehabilitation and is recently deceased (Lima, 2007). 
for a historical review). The most serious effects of high altitude on human physiology are due to the low oxygen partial pressure of the inspired air; consequently, different adjustments are needed to improve the tissue oxygen availability. Hypobaric hypoxia causes an increase in ventilation (see West, 1993), increases in arteriovenous $\mathrm{O}_{2}$ difference, hemoglobin concentration, and hematocrit (Ferretti et al., 1990a), profound effects on the structure and function of skeletal muscle tissue (Ferretti et al., 1990b; Hoppeler et al., 1990), acid-base alterations with an important incidence in the affinity of hemoglobin to oxygen (Cerretelli and Samaja, 2003), and elevated erythropoietin levels (Eckardt et al., 1989). Moreover, prolonged exposure to hypobaric hypoxia also induces a degree of physical deterioration, which increases with altitude (Kayser, 1994). This deleterious effect is reflected in a marked decrease in body weight, due in part to a reduction in muscle mass (Terrados, 1992). To prevent the negative effects of chronic hypoxia-exposure, several procedures alternating short hypoxia exposure with immediate recovery in normoxia have been proposed. These intermittent hypoxia-exposure procedures are performed in hypoxic chambers and have led to relevant findings, such as the efficacy of hypoxic versus normoxic training on $\mathrm{V}_{\mathrm{O}_{2 \max }}$ (Loeppky and Bynum, 1970); changes in the oxygen transport capacity of blood, which have a special incidence in altitude acclimatization (strong erythropoietic response, high affinity of hemoglobin to oxygen) (Schmidt et al., 1991; Knaupp et al., 1992); and an increase in resting ventilation and a reduction of the incidence and severity of acute mountain sickness (Beidleman et al., 2004). Thus, these exposure protocols have been evaluated as efficient methods for high altitude acclimatization (Wagner et al., 1987; Sutton et al., 1988; Richalet et al., 1992).

In collaboration with other authors, we have studied the effect of intermittent simulated altitude (in a hypobaric chamber) on human functional parameters commonly used to measure physical fitness. These studies show an improvement in the anaerobic threshold and the cardiovascular response to exercise in subjects with initially low or moderate physical levels (Rodriguez et al., 1999; Rodriquez et al., 2000; Casas et al., 2000a; Casas et al., 2000b). In the present study we analyze the basic mechanisms of the adaptive responses previously described in humans and elicited by intermittent hypoxia. For this purpose, we developed an animal experiment to apply techniques and methods that cannot be used in humans for ethical or technical reasons. We applied an intermittent hypobaric hypoxia (IHH) exposure protocol to laboratory rats in order to study myocardial morphofunctional parameters such as capillary and fiber density, fiber size and shape, capillary to fiber ratios, and maximal diffusion distance from surrounding capillaries to the fiber core. Preliminary results from this study were presented in the Annual Main Meeting of the Society for Experimental Biology (Barcelona, July 2005).

\section{MATERIALS AND METHODS}

\section{Animals}

A total of 58 male Sprague-Dawley rats with an age of 6 weeks at the beginning of the experiment were randomly divided into four groups. The first experimental group of 17 rats (named group $\mathrm{H}$, for hypoxic), with a mean body weight ( \pm SEM of $289 \pm 6.9 \mathrm{~g}$, was submitted to a program of IHH (described in detail later), and hearts were drawn at the end of this program. A second experimental group of 16 rats (named group P20, for posthypoxic 20 days), with a mean body weight of $303 \pm 5.8 \mathrm{~g}$, was simultaneously submitted to the same program, but myocardium samples were obtained 20 days after the end of the protocol. A third experimental group of 6 rats (named group P40, for posthypoxic 40 days), with a mean body weight of $290 \pm 6.9 \mathrm{~g}$, was simultaneously submitted to the same exposure program, but samples were obtained 40 days after the end of the protocol. Finally, 19 rats with a mean body weight of $303 \pm 5.1 \mathrm{~g}$ were used as a triple control group (named group $C$, for control). Control animals were maintained in the same conditions as the three experimental groups. Samples from 7 of the controls (group 
C1) were obtained at the same time as those from $\mathrm{H}$, samples from 8 of the controls (group C2) were obtained at the same time as those from P20, and, finally, samples from the 4 remaining controls (C3) were taken at the same time as those from $\mathrm{P} 40$.

The present study was authorized by the University of Barcelona's Ethical Committee for Animal Experimentation and ratified, in accordance with current Spanish legislation, by the Departament de Medi Ambient i Habitatge (file 1899) of the Government of Catalonia (Generalitat de Catalunya).

\section{Hypobaric chamber}

A hypobaric chamber was used to submit the rats to the IHH program. The total volume of the hypobaric chamber was approximately 450 $\mathrm{L}$, which allowed the housing of three rat cages. The chamber walls were made of metacrylate plastic, which facilitated observation of animal behavior during the protocol. Relative vacuum was developed by a rotational vacuum pump (TRIVAC D5E, Leybold, Köln, Germany) by regulating the airflow rate at the inlet with a micrometric valve. Inner pressure was controlled by two differential pressure sensors (ID 2000, Leybold, Köln, Germany) connected to a vacuum controller (Combivac IT23, Leybold, Köln, Germany) driving a diaphragm pressure regulator (MR16, Leybold, Köln, Germany). Depending on the simulated altitude to reach, a low-pressure set point was established in a control system. After the desired level was reached, the internal barometric pressure of the chamber was regulated and maintained by the control system.

\section{IHH program}

After a quarantine of 2 weeks, animals were moved into the conditioned room containing the hypobaric chamber. An initial period of 5 days, free of disturbance, was established for complete habituation. The IHH program consisted of 4-h sessions 5 days a week for 4 weeks and 2 additional days, thus completing 22 days of exposure to hypoxia ( $88 \mathrm{~h}$ in total). The simulated altitude reached during each session was $5000 \mathrm{~m}$ $(400 \mathrm{mmHg}=533 \mathrm{hPa}) . \mathrm{C}$ group was subjected to the same procedure, although the hypobaric chamber was open to room pressure.

\section{Sampling and histochemical procedures}

Animals were anesthetized with urethane (1.5 $\mathrm{g} / \mathrm{kg} \mathrm{BM})$, heart was extracted and weighed, and immediately soaked in 3-methyl-butane precooled to $-160^{\circ} \mathrm{C}$ and stored in liquid nitrogen until subsequent sectioning (Dubowitz, 1985). Serial transverse sections from the median and central part of the left ventricle were cut at a thickness of $14 \mu \mathrm{m}$ in a cryostat (Frigocut, Reichart-Jung, Heidelberg, Germany) at $-22^{\circ} \mathrm{C}$. Sections were mounted on gelatinized slides and incubated for $5 \mathrm{~min}$ in a buffered fixative (Viscor et al., 1992) to prevent shrinkage or wrinkling. After rinsing the slides thoroughly, we used the ATPase method developed by Fouces et al. (1993) to reveal muscle capillaries.

\section{Morphofunctional measurements}

Images of the stained sections were obtained using a light microscope (Olympus, BX40, Japan) connected to a digital camera (Hitachi, KP-C550, Chiyoda-ku, Japan). To ensure accurate calibration of all measurements, an image of a stage micrometer was obtained each time that images of samples were taken. Capillary density (CD), fiber density (FD), and the number of capillaries in contact with each fiber (NCF) were then empirically determined from $2 / 10^{5} \mu \mathrm{m}^{2}$ windows of tissue. Capillary and fiber counts were calculated to be expressed as capillaries and fibers per square millimeter. Fiber cross-sectional area (FCSA) and fiber perimeter (FPER) were determined directly using a personal computer connected to a digitizer tablet and SigmaScan software (Systet Software Gmbh, Erkrath, Germany) from digital images. Two indexes expressing the relationship between NCF and the FCSA (CCA $=\mathrm{NCF} / 10^{3}$ / FCSA $)$ or FPER $\left(\mathrm{CCP}=\mathrm{NCF} \cdot 10^{2} / \mathrm{FPER}\right)$ were also calculated. These indexes are considered a measure of the number of capillaries per 1000 $\mu \mathrm{m}^{2}$ of muscle FCSA and the number of capillaries per $100 \mu \mathrm{m}$ of muscle FPER. Capillary to fiber ratio $(\mathrm{C} / \mathrm{F})$ was also calculated as the $\mathrm{CD} /$ $\mathrm{CF}$ quotient. In addition, Feret diameter (FD) and shape factor (SF) were automatically determined for each fiber measured. The first parameter can be used as an accurate estimation of the maximal diffusion distance (MDD) between capillary and the central region of the fiber, whereas the second indicates the degree 
of adjustment of the fiber transverse section to a circular shape $(\mathrm{SF}=1$ for a perfect circle). (See Table 2 for definitions of the preceding abbreviations.)

\section{Statistics}

Data for all the parameters are expressed as sample means \pm standard deviation. To test data for normality, the Kolmogorov-Smirnov test (with the Lilliefors correction) was used. Comparisons between the two experimental groups and the control were analyzed by a oneway ANOVA test. Afterward, a multiple comparison test by the Holm-Sidak procedure was run to determine the differences between each pair of experimental and control conditions. All statistical tests were performed using Sigma Stat (SPSS Science, USA) software, with significance at $p<0.05$.

\section{RESULTS}

Since no statistically significant differences were found between C1, C2, and C3 for any of the parameters, unless otherwise indicated, these three control groups were grouped for all figures and tables and named group $C$.

\section{Body weights}

The four groups showed similar growth kinetics, and no statistical differences were found between any of them when body weights were compared. Likewise, neither the heart weight nor the heart/BW ratio showed significant differences between control (C1, C2 and C3) and their corresponding hypoxic counterparts $(\mathrm{H}$, P20, and P40) (Table 1).

\section{Capillary supply and fiber morphometry}

A clear increasing trend was found in capillary supply parameters $(\mathrm{CD}, \mathrm{FD}, \mathrm{C} / \mathrm{F}, \mathrm{NCF}$,
CCA, and CCP), while for morphometrical fiber values (FCSA, FPER and MDD) a reduction was evident when comparing the $\mathrm{C}$ to $\mathrm{H}$ groups (Table 2). Both patterns persisted and were even intensified 20 days after the end of the IHH program (group P20); however, most parameters recovered to initial levels after 40 days from the end the IHHE program (group P40). A Cartesian graph showing FD plotted against $\mathrm{CD}$ shows a clear segregation of $\mathrm{H}$ and P20, both with high FD and CD, from $C$, which showed lower FD and CD (Fig. 1). On the other hand, P40 was also segregated, with low FD but high $C D$, from the other hypoxic groups. A fiber percentage distribution plot in $100-\mu \mathrm{m}^{2}$ ranks of FCSA depicts a similar behavior for $\mathrm{C}$ and $\mathrm{P} 40$, on the one hand, and $\mathrm{H}$ and $\mathrm{P} 20$, on the other (Fig. 2). In C and P40, most of the fibers measured around $300 \mu \mathrm{m}^{2}$, which contrasts with the reduced FCSA values $\left(200 \mu \mathrm{m}^{2}\right)$ for both C and P20.

The most marked differences between $C$ and P20 were found in the relative capillarization indexes, CCA and CCP (with increases of 33\% and $23 \%$, respectively), showing the combined effect of increased NCF and decreased FCSA or FPER. Finally, it is of interest to note that all the changes in capillarization and fiber morphometry reported here occurred without alterations in fiber shape, as demonstrated by the absence of differences in SF, an index that indicates this parameter.

\section{DISCUSSION}

Many studies have reported that chronic hypoxia induces deleterious effects on the organism, such as hypertrophy of the right ventricle (Banchero et al., 1987; Lewis et al., 1999), alterations in protein metabolism, and anorexia, which provokes weight loss as a result of a de-

Table 1. Body and Heart Weights in Control and Hypoxic Rats.

\begin{tabular}{lcccr}
\hline & Body weight $(g)$ & Heart weight $(g)$ & Heart/BW ratio (\%) & $\mathrm{n}$ \\
\hline C1 & $393 \pm 8.8$ & $1.252 \pm 0.04$ & $0.319 \pm 0.01$ & 7 \\
H & $391 \pm 8.7$ & $1.238 \pm 0.04$ & $0.316 \pm 0.01$ & 17 \\
C2 & $408 \pm 7.5$ & $1.374 \pm 0.09$ & $0.336 \pm 0.02$ & 8 \\
P20 & $420 \pm 7.9$ & $1.293 \pm 0.05$ & $0.307 \pm 0.01$ & 16 \\
C3 & $420 \pm 11.0$ & $1.215 \pm 0.05$ & $0.290 \pm 0.01$ & 4 \\
P40 & $431 \pm 10.9$ & $1.309 \pm 0.05$ & $0.304 \pm 0.01$ & 6 \\
\hline
\end{tabular}


Table 2. Capillary Supply and Morphometrical Fiber Parameters in Rat Myocardium of Control and Hypoxic Rats.

\begin{tabular}{lcccc}
\hline & C & $H$ & $P 20$ & $P 40$ \\
\hline CD (capillaries $\left./ \mathrm{mm}^{2}\right)$ & $4,124 \pm 1.95$ & $4,733 \pm 147$ & $4,816 \pm 214$ & $4,794 \pm 58$ \\
FD (fibers $\left./ \mathrm{mm}^{2}\right)$ & $2,844 \pm 137^{\mathrm{b}}$ & $3,125 \pm 105$ & $3,284 \pm 92^{\mathrm{f}}$ & $2,751 \pm 71$ \\
C /F & $1.46 \pm 0.06$ & $1.52 \pm 0.05$ & $1.53 \pm 0.04$ & $1.70 \pm 0.07$ \\
NCF & $4.04 \pm 0.2^{\mathrm{b}, \mathrm{c}}$ & $4.31 \pm 0.10^{\mathrm{d}, \mathrm{e}}$ & $4.50 \pm 0.11$ & $4.95 \pm 0.16$ \\
FCSA $\left(\mathrm{mm}^{2}\right)$ & $273 \pm 12.5^{\mathrm{a}, \mathrm{b}}$ & $235 \pm 6.3$ & $227 \pm 7.3$ & $272 \pm 11.0$ \\
FPER $(\mathrm{mm})$ & $68.5 \pm 1.5^{\mathrm{a}, \mathrm{b}}$ & $63.5 \pm 1.0$ & $61.8 \pm 1.2^{\mathrm{f}}$ & $67.3 \pm 1.6$ \\
CCA & $15.0 \pm 0.8^{\mathrm{a}, \mathrm{b}, \mathrm{c}}$ & $18.4 \pm 0.5$ & $19.9 \pm 0.5$ & $18.4 \pm 1.0$ \\
CCP & $5.91 \pm 0.19^{\mathrm{a}, \mathrm{b}, \mathrm{c}}$ & $6.79 \pm 0.16$ & $7.29 \pm 0.15$ & $7.39 \pm 0.33$ \\
MDD $(\mathrm{mm})$ & $18.2 \pm 0.4^{\mathrm{a}, \mathrm{b}, \mathrm{c}}$ & $16.9 \pm 0.2$ & $16.6 \pm 0.3^{\mathrm{f}}$ & $18.3 \pm 0.4$ \\
SF & $0.713 \pm 0.004$ & $0.714 \pm 0.004$ & $0.728 \pm 0.007$ & $0.739 \pm 0.008$ \\
\hline
\end{tabular}

crease in muscular mass (see, for example, Snyder et al., 1985; Singh and Selvamurthy, 1993; Morel et al., 2005). Our first aim was to examine whether IHH conditions induced similar changes in muscle mass and weight. When the total body weight of hypoxic animals was compared to controls, no differences were found. Moreover, no significant differences between hypoxic and control groups were observed when heart weight and heart/body weight ratios were considered. These findings indicate that neither right ventricle hypertrophy nor skeletal muscle atrophy occurred.

After the pioneering study by Valdivia (1958), which reported an increase in CD in muscle tissue from animals native to the Peruvian mountains, extensive research on heart muscle in several species has been performed and has provided contrasting results. Several authors report no changes in CD, FCSA, or C/F in the myocardium of rats after exposure to simulated altitude between 4,000 to 5,000 m (Pietschman and Bartels, 1985; Lewis et al., 1999). These results contrast with those described by Kayar and Banchero (1985) and León-Velarde and colleagues (1993), who detected increases in $\mathrm{CD}$ and $\mathrm{C} / \mathrm{F}$ and reductions in FCSA and diffusion distances (MDD) in the heart muscle fibers of guinea pig and Andean coots, respectively, in response to hypoxic con-

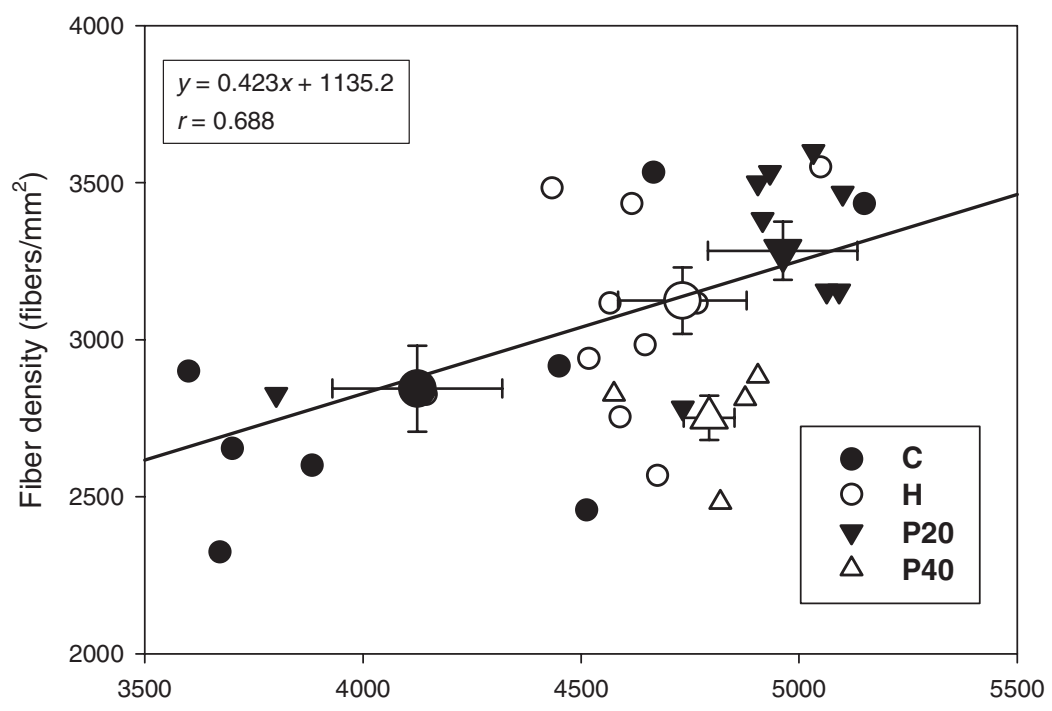

FIG. 1. Capillary and fiber-density relationship in rat myocardium. The solid line represents the regression of all values, excluding data from P40 group. Regression equation and the coefficient of correlation are shown in the upper-left corner of the graph. 


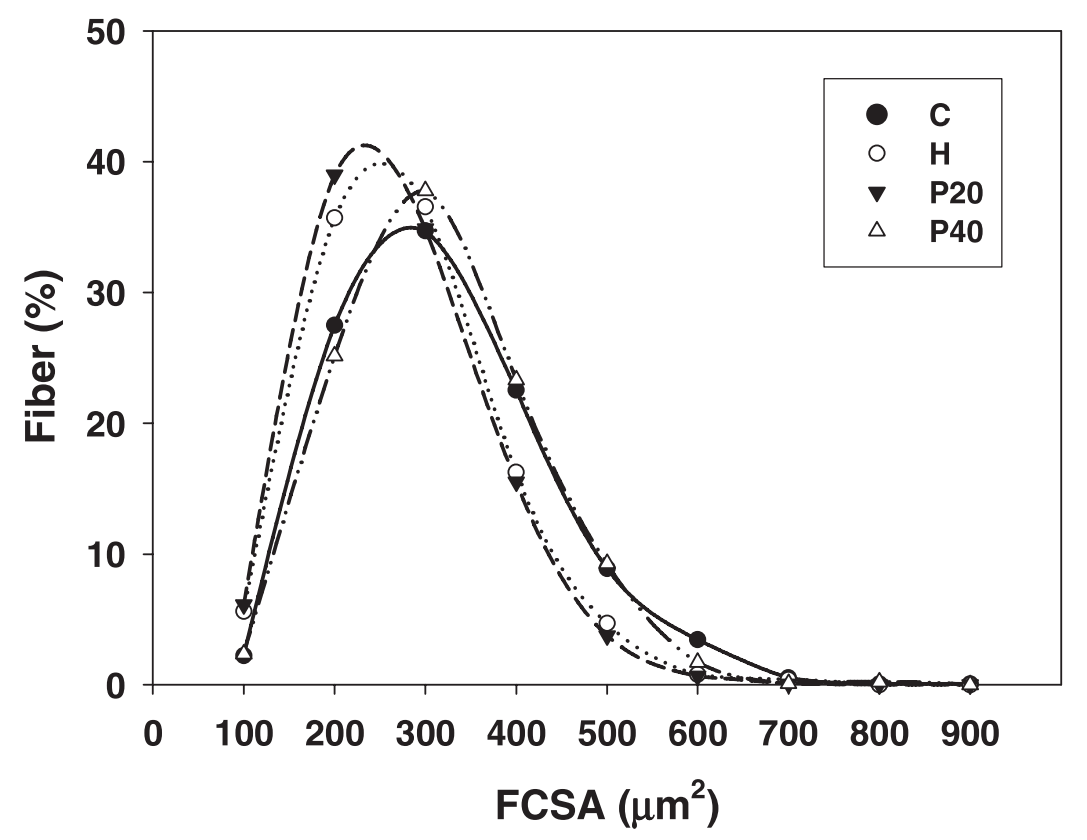

FIG. 2. Percentage distribution with $100-\mu \mathrm{m}^{2}$ ranks of fiber cross-sectional area of myocardium fibers.

ditions. More contrasting results were reported by Clark and Smith (1978) in the hypoxic right ventricle of rats exposed to $5250 \mathrm{~m}$ for 34 days. These authors described increases in FCSA, with reductions in $\mathrm{CD}$ and no changes in NCF. We found progressive and significant increases in $\mathrm{CD}$ and FD in $\mathrm{H}$ and P20, which were accompanied by significant reductions in FCSA, FPER, and MDD. An increase in CD improves irrigation to myocardial cells, and the reduction in fiber morphometrical parameters indicates a better oxygen supply in relation to fiber surface area, that is, more efficient $\mathrm{O}_{2}$ delivery to mitochondria. Moreover, we also detected higher values of NCF in all hypoxic groups, thereby indicating the occurrence of angiogenesis. The most significant differences between control and hypoxic groups were found when combining morphometrical (FCSA, FPER) and vascular (NCF) fiber parameters in the indexes CCA and CCP. The significant increases in these indexes indicate that the myocardium of hypoxic groups had more capillaries per unit fiber area and unit fiber perimeter. These changes occurred without concomitant alterations in fiber morphology, as deduced from the lack of differences in SF.

It is of interest to note that the parameters re- lated to fiber morphometry (FD, FCSA, FPER and MDD) in $\mathrm{P} 40$ recovered to $C$ values, while those parameters related to total myocardium vascularization $(\mathrm{CD}, \mathrm{C} / \mathrm{F})$ and fiber vascularization (NCF, CCP, CCA) maintained higher values in P40 than $\mathrm{C}$. $\mathrm{H}$ and $\mathrm{P} 20$ showed similar coordinates segregated from $C$. A linear relationship between $\mathrm{C}, \mathrm{H}$, and P20 was observed, indicating that increases in $C D$ matched those in FD (reduction in FCSA). In contrast, 40 days after the end of the IHH protocol, P40 maintained high vascularization levels, but with increased fiber size (lower FD). Figure 2 reinforces this statement, showing that two subgroups are formed when considering a distribution of fibers in ranks of $100 \mu \mathrm{m}^{2}$ : on the one hand, $\mathrm{H}$ and P20 presented most fibers around $230 \mu \mathrm{m}^{2}$ and on the other, $\mathrm{C}$ and $\mathrm{P} 40$ grouped, showing fibers around $300 \mu \mathrm{m}^{2}$. On the basis of our findings, we propose that increases in myocardial fiber vascularization and morphometry require some time (about 20 days) after the hypoxic stimulus to reach the highest values. In addition, increases in vascularization persist longer after the cessation of hypoxic stimulus than changes in fiber morphometry. We hypothesize that angiogenesis requires mechanisms of vascular remodeling 
and new protein synthesis for vascular growth that could have a higher energetic cost or a longer time course, or both, than those mechanisms that induce fiber structural changes, such as a reduction in fiber size. This hypothesis would support the observation that vascular changes persist for longer. This hypothesis is further supported by the recognition that activation of specific genes is a crucial mechanism by which hypoxia triggers long-term adaptive responses. A recent review by Lahiri and colleagues (2006) analyzed the function of reactive oxygen species (ROS) as signal transducers for specialized $\mathrm{O}_{2}$-sensing cells. These cells induce specific genes involved in oxygen homeostasis after the mediation of hypoxia-inducible factor (HIF-1 $\alpha)$, in turn upregulating vascular endothelial growth factor (VEGF), which are strongly activated after intermittent hypoxia (Yuan et al., 2005).

Consistent with the results of other studies that used distinct protocols of intermittent hypoxia (Tin'kov and Aksenov, 2002; Park et al., 2007), our findings support the clinical use of $\mathrm{IHH}$ for myocardial recovery, since this protocol improves oxygen delivery to myocardium fibers. Our results give support to previous reports by E. Marticorena, in Peru, who originally described a procedure for cardiac recovery. In this protocol, patients were brought to altitude $(5000 \mathrm{~m})$ as a part of a coronary cardiac rehabilitation program (Marticorena, 2001; Marticorena et al., 2001). These authors also detected increases in plasmatic levels of NO when subjects with cardiac coronary disease were submitted to a simulated altitude of $4000 \mathrm{~m}$ in a hypobaric chamber. On the basis of these findings, these authors proposed that the mechanisms triggered by hypoxia contribute to coronary rehabilitation (Marticorena, 1998). Moreover, using echocardiography, Valle and colleagues (2006) observed that in subjects with chronic coronary disease $\mathrm{IHH}$ improved cardiac perfusion. To our knowledge, our results provide the first histochemical evidence to support these reports.

On the basis of our observations, we conclude that the IHH protocol developed in this study is a suitable method for hypoxia acclimatization, since neither right ventricle hypertrophy nor skeletal muscle atrophy oc- curred. Since increases in myocardium vascularization persist longer than changes in fiber morphometry, we propose that IHH protocols could make a valuable contribution to cardiac rehabilitation, especially in Central Asia or Andean regions, where intermittent exposure to altitude can easily be accomplished at low cost.

Further studies should be undertaken to clarify some apparent discrepancies between the effects of chronic and intermittent hypoxia. Factors such as the duration and intensity of the intermittent hypoxic stimulus, the persistency of the previously described morphofunctional changes in the myocardium, and the IHH responsiveness in other species are important issues to be considered.

\section{ACKNOWLEDGMENTS}

This study was supported by grant BFI200303439 through the Plan Nacional I+D+I of Spain's Ministerio de Educación y Ciencia. The authors thank Robin Rycroft (Language Advisory Service-U.B.) for editing the manuscript.

\section{REFERENCES}

Banchero N., Van B.M., and Smith S.L. (1987). Ventricular weights in guinea pigs acclimated to cold plus hypoxia. Proc. Soc. Exp. Biol. Med. 186:36-40.

Beidleman B.A., Muza S.R., Fulco C.S., Cymerman A., Ditzler D., Stulz D., Staab J.E., Skrinar G.S., Lewis S.F., and Sawka M.N. (2004). Intermittent altitude exposures reduce acute mountain sickness at $4300 \mathrm{~m}$. Clin. Sci. (London) 106:321-328.

Bert P. (1878) La pression barométrique. Recherches de physiologie expérimentale. Masson, Paris, France.

Casas H., Casas M., Ricart A., Rama R., Ibañez J., Palacios L., Rodriguez F.A., Ventura J.L., Viscor G., and Pages T. (2000a). Effectiveness of three short intermittent hypobaric hypoxia protocols: hematological responses. J. Exerc. Physiol. 3:38-45.

Casas M., Casas H., Pages T., Rama R., Ricart A., Ventura J.L., Ibañez J., Rodriguez F.A., and Viscor G. (2000b). Intermittent hypobaric hypoxia induces altitude acclimation and improves the lactate threshold. Aviat. Space Environ. Med. 71:125-130.

Cerretelli P., and Samaja M. (2003). Acid-base balance at exercise in normoxia and in chronic hypoxia. Revisiting the "lactate paradox." Eur. J. Appl. Physiol. 90: 431-448. 
Clark D.R., and Smith P. (1978). Capillary density and muscle-fiber size in the hearts of rats subjected to simulated high-altitude. Cardiovasc. Res. 12:578-584.

Dubowitz, V. (1985). Muscle Biopsy: A Practical Approach. Baillière Tindall, London, UK.

Eckardt K.U., Boutellier U., Kurtz A., Schopen M., Koller E.A., and Bauer C. (1989). Rate of erythropoietin formation in humans in response to acute hypobaric hypoxia. J. Appl. Physiol. 66:1785-1788.

Ferretti G., Boutellier U., Pendergast D.R., Moia C., Minetti A.E., Howald H., and Di Prampero P.E. (1990a). Oxygen transport system before and after exposure to chronic hypoxia. Int. J. Sports Med. 11:S15-S20.

Ferretti G., Hauser H., and Di Prampero P.E. (1990b). Maximal muscular power before and after exposure to chronic hypoxia. Int. J. Sports Med. 11:S31-S34.

Fouces V., Torrella J.R., Palomeque J., and Viscor G. (1993). A histochemical ATPase method for the demonstration of the muscle capillary network. J. Histochem. Cytochem. 41:283-289.

Hoppeler H., Kleiner E., Schlegel C., Claassen H., Howald H., Kayar S.R., and Cerretelli P. (1990). II. Morphological adaptations of human skeletal muscle to chronic hypoxia. Int. J. Sports Med. 11:S3-S9.

Kayar S.R., and Banchero N. (1985). Myocardial capillarity in acclimation to hypoxia. Eur. J. Physiol. 404:319-325.

Kayser B. (1994). Factors limiting exercise performance in man at high altitude, PhD thesis, Université de Genève.

Kellogg R.H. (1978). "La Pression barométrique": Paul Bert's hypoxia theory and its critics. Respir. Physiol. 34:1-28.

Knaupp W., Khilnani S., Sherwood J., Scharf S., and Steinberg H. (1992). Erythropoietin response to acute normobaric hypoxia in humans. J. Appl. Physiol. 73:937-940.

Lahiri S., Roy A., Baby S.M., Hoshi T., Semenza G.L., and Prabhakar N.R. (2006). Oxygen sensing in the body. Prog. Biophys. Mol. Biol. 91:249-286.

Leon-Velarde F., Sanchez J., Bigard A.X., Brunet A., Lesty C., and Monge, C. (1993). High-altitude tissue adaptation in Andean coots. J. Comp. Physiol. B 163:52-58.

Lewis A.M., Mathieu-Costello O., McMillan P.J., and Gilbert R.D. (1999). Effects of long-term, high-altitude hypoxia on the capillarity of the ovine fetal heart. Am. J. Physiol. 277:H756.

Loeppky J.A., and Bynum W.A. (1970). Effects of periodic exposure to hypobaria and exercise on physical work capacity. J. Sports Med. Phys. Fitness 10:238-247.

Marticorena E.A. (1998). Bases moleculares hipóxicas en rehabilitación cardíaca coronaria con altura natural y simulada. Rev. Peruana Cardiol. 24:177-186.

Marticorena, E.A. (2001). Utilización de la altura natural y simulada en rehabilitación cardíaca coronaria. Acta Andina 9:63.

Marticorena E.A., Marticorena J.M., Gutierrez I., Rodriguez V., Fernandez-Davila L., Oyola L., Oré R., Contreras A., Valdivia L., Robles J., and Florentini E. (2001). Factor relajante del endotelio (NO) en rehabilitación coronaria con cámara hipobárica. Rev. Peruana Cardiol. 27:148-149.
Morel O.E., Aubert R., Richalet J.P., and Chapelot D. (2005). Simulated high altitude selectively decreases protein intake and lean mass gain in rats. Physiol. Behav. 86:145-153.

Park A.M., Nagase H., Kumar S.V., and Suzuki Y.J. (2007). Acute intermittent hypoxia activates myocardial cell survival signalling. Am. J. Heart Circ. Physiol. 292:H751-H757.

Pietschmann M., and Bartels H. (1985). Cellular hyperplasia and hypertrophy, capillary proliferation and myoglobin concentration in the heart of newborn and adult-rats at high altitude. Resp. Physiol. 59:347360.

Richalet J.P., Bittel J., Herry J.P., Savourey G., Le Trong J.L., Auvert J.F., and Janin C. (1992). Use of a hypobaric chamber for pre-acclimatization before climbing Mount Everest. Int. J. Sports Med. 13:S216-S220.

Rodriguez F.A., Casas H., Casas M., Pages T., Rama R., Ricart A., Ventura J.L., and Ibanez J., and Viscor G. (1999). Intermittent hypobaric hypoxia stimulates erythropoiesis and improves aerobic capacity. Med. Sci. Sports Exerc. 31:264-268.

Rodriguez F.A., Ventura J.L., Casas M., Casas H., Pages T., Rama R., Ricart A., Palacios L., and Viscor G. (2000). Erythropoietin acute reaction and haematological adaptations to short, intermittent hypobaric hypoxia. Eur. J. Appl. Physiol. 82:170-177.

Schmidt W., Eckardt K.U., Strauch S., and Bauer C. (1991). Effects of maximal and submaximal exercise under normoxic and hypoxic conditions on serum erythropoietin level. Int. J. Sports Med. 12:457-461.

Singh S.B., and Selvamurthy W. (1993). Effect of intermittent chronic exposure to hypoxia on feeding-behavior of rats. Int. J. Biometeorol. 37:200-202.

Snyder G.K., Wilcox E.E., and Burnham E.W. (1985). Effects of hypoxia on muscle capillarity in rats. Resp. Physiol. 62:135-140.

Sutton J.R., Reeves J.T., Wagner P.D., Groves B.M., Cyberman A., Malconian M.K., Rock P.B., Young P.M., Walter S.D., and Houston C.S. (1988). Operation Everest II: oxygen transport during exercise at extreme simulated altitude. J. Appl. Physiol. 64:1039-1321.

Terrados N. (1992). Altitude training and muscular metabolism. Int. J. Sports Med. 13:S206-S209.

Tin'kov A.N., and Aksenov V.A. (2002). Effects of intermittent hypobaric hypoxia on blood lipid concentrations in male coronary heart disease patients. High Alt. Med. Biol. 3:277-282.

Valdivia E. (1958). Total capillary bed in striated muscles of guinea pigs native to the Peruvian mountains. Am. J. Physiol. 194:585-589.

Valle M.D., Garcia-Godos F., Woolcott O.O., Marticorena J.M., Rodriguez V., Gutierrez I., Fernandez-Davila L., Contreras A., Valdivia L., Robles J., and Marticorena E.A. (2006). Improvement of myocardial perfusion in coronary patients after intermittent hypobaric hypoxia. J. Nucl. Cardiol. 13:69-74.

Viscor G., Torrella J.R., Fouces V., and Palomeque J. (1992). Skeletal muscle capillarization and fiber types 
in urban and homing pigeons (Columba livia). Comp. Biochem. Physiol. 101A:751-757.

Wagner P.D., Sutton J.R., Reeves J.T., Cymerman A., Groves B.M., and Malconian M.K. (1987). Operation Everest II: pulmonary gas exchange during a simulated ascent of Mt. Everest. J. Appl. Physiol. 63:2348-2359.

West J.B. (1993). Acclimatization and tolerance to extreme altitude. J. Wilderness Med. 4:17-26.

Yuan G., Nanduri J., Bhasker C.R., Semenza G.L., and Prabhakar N.R. (2005). $\mathrm{Ca}^{2+} /$ calmodulin kinase-dependent activation of hypoxia inducible factor 1 transcriptional activity in cells subjected to intermittent hypoxia. J. Biol. Chem. 280:4321-4328.
Address reprint requests to:

Ginés Viscor

Departament de Fisiologia, Facultat de Biologia

Universitat de Barcelona

Av. Diagonal, 645; E08028

Barcelona, Spain

E-mail: gviscor@ub.edu

Received April 12, 2007; accepted in final form June 5, 2007. 